\title{
Tyrosine Phosphorylation Sites in ephrinB2 Are Required for Hippocampal Long-Term Potentiation But Not Long-Term Depression
}

\author{
Farima Bouzioukh, ${ }^{1}$ George A. Wilkinson, ${ }^{1}$ Giselind Adelmann, ${ }^{3}$ Michael Frotscher, ${ }^{3}$ Valentin Stein, ${ }^{2}$ and \\ Rüdiger Klein ${ }^{1}$ \\ ${ }^{1}$ Department of Molecular Neurobiology and 2 Synaptic Receptor Trafficking Group, Max-Planck Institute of Neurobiology, 82152 Munich-Martinsried, \\ Germany, and ${ }^{3}$ Institute for Anatomy and Cell Biology, University of Freiburg, 79001 Freiburg, Germany
}

\begin{abstract}
Long-lasting changes in synaptic function are thought to be the cellular basis for learning and memory and for activity-dependent plasticity during development. Long-term potentiation (LTP) and long-term depression (LTD) are two opposing forms of synaptic plasticity that help fine tune neural connections and possibly serve to store information in the brain. Eph receptor tyrosine kinases and their transmembrane ligands, the ephrinBs, have essential roles in certain forms of synaptic plasticity. At the CA3-CA1 hippocampal synapse, EphB2 and EphA4 receptors are critically involved in long-term plasticity independent of their cytoplasmic domains, suggesting that ephrinBs are the active signaling partners. In cell-based assays, ephrinB reverse signaling was previously shown to involve phosphotyrosine-dependent and postsynaptic density-95/Discs large/zona occludens-1 (PDZ) domain interaction-dependent pathways. Which reverse signaling mode is required at hippocampal synapses is unknown. To address this question, we used knock-in mice expressing mutant isoforms of ephrin $\mathrm{B} 2$ that are deficient in specific aspects of reverse signaling. Our analysis revealed that tyrosine phosphorylation sites in ephrinB2 are required to mediate normal hippocampal LTP, but not for LTD. Conversely, ephrinB2 lacking the C-terminal PDZ interaction site, but competent to undergo tyrosine phosphorylation, cannot mediate either form of long-term plasticity. Our results provide the first evidence for phosphotyrosine-dependent ephrinB reverse signaling in a neuronal network and for differential ephrinB2 reverse signaling in two forms of synaptic plasticity.
\end{abstract}

Key words: ephrinB2; tyrosine phosphorylation; hippocampus; plasticity; long-term potentiation; long-term depression

\section{Introduction}

Long-lasting changes in synaptic strength [long-term potentiation (LTP) or long-term depression (LTD)] are thought to be the cellular basis for learning and memory and for activitydependent plasticity during development. Glutamate, the major excitatory neurotransmitter in the CNS, binds to postsynaptic AMPA or NMDA receptors. Although AMPA receptors mediate most of the rapid EPSCs, the degree of NMDA receptor activation and resultant differences in postsynaptic calcium dictate whether LTP or LTD occur (Lisman, 1989; Artola and Singer, 1993; Cummings et al., 1996; Malenka and Nicoll, 1999; Yang et al., 1999; Malenka and Bear, 2004).

LTP and LTD are complex phenomena regulated by many signaling pathways (Xia and Storm, 2005; Lee, 2006) and associated with modifications of postsynaptic receptor properties and

Received April 2, 2007; revised Aug. 20, 2007; accepted Aug. 22, 2007.

This work was supported in part by the Max-Planck Society, Deutsche Forschungsgemeinschaft Grants SFB391 and SPP1172, and the European Union (ENDOTRACK). F.B. was a European Molecular Biology Organization fellow. We thank V. Staiger, J. Bailey, M. Braun, D. Büringer, and A. Schneider for valuable technical help and I. Kadow and A. Acker-Palmer for valuable comments and critical reading of this manuscript.

Correspondence should be addressed to Dr. Rüdiger Klein, Department of Molecular Neurobiology, Max-Planck Institute of Neurobiology, Am Klopferspitz 18, 82152 Munich-Martinsried, Germany. E-mail: rklein@neuro.mpg.de. D01:10.1523/JNEUROSCI.3393-07.2007

Copyright $\odot 2007$ Society for Neuroscience 0270-6474/07/2711279-10\$15.00/0 changes in dendritic spines (Luscher et al., 2000; Muller et al., 2002). Hippocampal LTP and LTD require the presence of members of the Eph receptor tyrosine kinase (RTK) family and their transmembrane ligands, the ephrinBs. Unlike other RTK ligands, ephrins have their own signaling potential, in that binding between Eph- and ephrin-expressing cells stimulates signaling cascades within the Eph-bearing cell ("forward signaling"), as well as the ephrin-bearing cell ("reverse signaling") (Egea and Klein, 2007). In the hippocampus, the Eph/ephrin signaling system is used differently depending on the synapses involved. At the mossy fiber-CA3 synapse, NMDA-independent LTP requires ephrinB3 in presynaptic dentate gyrus neurons (Contractor et al., 2002; Armstrong et al., 2006). Conversely at the CA3-CA1 synapse, ephrinB2 and ephrinB3 function mainly postsynaptically in CA1 neurons (Grunwald et al., 2001, 2004; Henderson et al., 2001; Rodenas-Ruano et al., 2006). Their possible binding partners, EphB2 and EphA4, are expressed by presynaptic (CA3) and postsynaptic (CA1) neurons (Grunwald et al., 2004; Tremblay et al., 2007).

The mechanisms of ephrinB reverse signaling in functional neuronal networks are not well understood apart from their interactions with metabotropic glutamate receptors (Calo et al., 2005). Eph-ephrinB interaction triggers the activation of Src family tyrosine kinases (SFKs) (Palmer et al., 2002) and tyrosine 
phosphorylation of the ephrinB cytoplasmic tail. The adaptor protein Grb4 associates with tyrosine-phosphorylated ephrinBs (Cowan and Henkemeyer, 2001) and mediates morphogenesis of dendritic spines in culture (Segura et al., 2007). EphrinBs also have a C-terminal motif recognized by postsynaptic density-95 (PSD-95)/Discs large/zona occludens-1 (PDZ) domaincontaining proteins (Lu et al., 2001; Palmer et al., 2002) and references within). Recent reports involving knock-in mice indicate important functions for the ephrinB PDZ domain interaction motif during midline fusion of palatal shelves (Davy et al., 2004) and for remodeling of the lymphatic vasculature (Makinen et al., 2005). Unexpectedly, phosphotyrosine-dependent reverse signaling by ephrinB2 was not critical for lymphatic development (Makinen et al., 2005). Using the same knock-in mice, we now find that phosphotyrosine-dependent reverse signaling by ephrinB2 is essential for CA3-CA1 hippocampal LTP but not for LTD and depotentiation. Our results provide the first evidence for a critical function of tyrosine phosphorylated ephrinBs in a neuronal network and for differential ephrinB2 reverse signaling in two forms of synaptic plasticity.

\section{Materials and Methods}

Mice

The generation and genotypic analysis of ephrinB2 knock-in mutant and wild-type control mice has been described previously (Makinen et al., 2005). Briefly, mouse cDNAs encoding ephrinB2 mutant isoforms or wild-type ephrinB2 were inserted into the ephrinB2 gene locus in frame with exon 1 . The ephrinB2 ${ }^{\Delta \mathrm{V}}$ isoform carries a deletion of the $\mathrm{C}$-terminal valine within the PDZ interaction site. The ephrinB2 ${ }^{5 \mathrm{~F}}$ isoform is deficient in tyrosine phosphorylation and carries phenylalanine $(\mathrm{F})$ in place of tyrosine residues, with one exception: Tyr 333 was specified to encode leucine, rather than phenylalanine. We had previously proposed to rename this allele ephrinB2 ${ }^{5 Y}$ (Makinen et al., 2005) and will use this nomenclature here. Although the Tyr 333 to Leu substitution is close to the $\mathrm{C}$ terminus ( -4 position) within the sequence motif recognized by $\mathrm{PDZ}$ domain-containing proteins, ephrinB2 ${ }^{5 \mathrm{Y}}$ protein efficiently interacts with glutamate receptor-interacting protein-1 (GRIP1) (supplemental Fig. S1, available at www.jneurosci.org as supplemental material). Mutant and wild-type knock-in mice were maintained in a heterozygous state on a CD1 background (five backcrosses). Wild-type control knock-in mice were taken from heterozygous crosses of ephrinB2 $2^{W T /+}$ mice. Both mutant lines when bred onto the outbred CD1 background survived to adulthood and did not display obvious lymphatic abnormalities (data not shown).

\section{Primary culture and immunofluorescence}

Hippocampal neuron cultures were prepared from embryonic day 16.5 (E16.5) CD1 embryos and cultured for 2 or $20 \mathrm{~d}$ in vitro (DIV) in Neurobasal medium plus B27 (Invitrogen, Karlsruhe, Germany). Forebrain neuron cultures were prepared from E16.5 CD1 embryos and cultured for 8 DIV in the same conditions. For stimulation with clustered EphB4 receptor, EphB4-Fc (R \& D Systems, Wiesbaden, Germany) was incubated in an anti-human Fc antibody (R \& D Systems) for $1 \mathrm{~h}$. Clustered receptor $(2 \mu \mathrm{g} / \mathrm{ml})$ was added for $40 \mathrm{~min}$. Neurons were stained as described previously (Grunwald et al., 2001). Clusters were analyzed using MetaMorph software. Microtubule-associated protein 2 (MAP2) staining was done on $50 \mu \mathrm{m}$ vibratome sections from adult mice. Primary MAP2 antibodies were from Sigma (Taufkirchen, Germany; M9942, 1:500), and secondary antibodies were anti-mouse IgG Cy5 (1:200; Jackson ImmunoResearch, Newmarket, Suffolk, UK).

\section{Biochemistry}

HeLa cells were transiently transfected by the calcium phosphate method. Cells were lysed in Triton lysis buffer supplemented with Complete protease inhibitors (Roche, Mannheim, Germany). Clarified lysates were subjected to green fluorescent protein (GFP) immune precipitation using standard protocols.

\section{Phosphorylation assays}

Pervanadate was generated by adding $1.1 \mu \mathrm{l}$ of hydrogen peroxide to $1 \mathrm{ml}$ of $100 \mathrm{~mm}$ vanadate stocks and added to acute slices at a final concentration of $0.1 \mathrm{~mm}$ for $10 \mathrm{~min}$. After three washes in normal artificial CSF (ACSF), slices were homogenized in lysis buffer. Lysates were immune precipitated using anti-ephrinB2 antibody (R \& D Systems) and subjected to Western blot analysis for anti-phosphotyrosine (clone 4G10; Roche).

Forebrain neurons at $8 \mathrm{DIV}$ were stimulated with EphB4-Fc or Fc preclustered for $1 \mathrm{~h}$ at room temperature using goat anti-human IgG (Jackson ImmunoResearch). After stimulation, neurons were washed with cold PBS and lysed in the lysis buffer [50 mM Tris, pH 7.5, $150 \mathrm{~mm}$ $\mathrm{NaCl}, 1 \%$ Triton $\mathrm{X}-100,1 \mathrm{~mm}$ sodium orthovanadate, and protease inhibitors (Complete tablets; Roche)] to check NMDA receptor subunit $2 \mathrm{~A}$ (NR2A) phosphorylation, or in the cell extraction buffer recommended by the manufacturer for the pY418 Src ELISA kit (Biosource, Nivelles, Belgium). The lysates were centrifuged at $13,000 \mathrm{rpm}$ for $10 \mathrm{~min}$ at $4^{\circ} \mathrm{C}$. Protein concentrations were determined with Bradford reagent (BioRad, Munich, Germany). The clear lysates were used to check NR2A phosphorylation or Src activity. The pY418 Src ELISA kit was used according to the manufacturer's specifications. Western blotting was performed with the following primary antibodies: anti-NR2A (1:1000; Affinity BioReagents, Golden, CO) and anti-pY1325 NR2A (1:1000; Abcam, Cambridge, UK).

\section{Electron microscopy}

Ultrastructural analysis of CA1 hippocampal region synapses was performed as described previously (Grunwald et al., 2001). EM immunocytochemistry experiments were performed as described previously (Grunwald et al., 2004). The thickness of the PSDs was measured using a perpendicular line drawn at the midpoint of the length of the PSD.

\section{Electrophysiology}

Field recording. LTD experiments were performed with mice $14-20 \mathrm{~d}$ old [postnatal day 14 (P14) to P20], and mice used for LTP and depotentiation experiments were 5-8 weeks old as in the previous studies (Grunwald et al., 2001, 2004). For each experimental condition, acute slices of 4-10 animals were used. Synaptic responses were evoked in the CA3 region of the hippocampus by stimulating the Schaffer collaterals with $0.2 \mathrm{~ms}$ pulses. Field EPSPs (fEPSPs) were recorded extracellularly in the stratum radiatum of the CA1 region using glass microelectrodes (Harvard Apparatus, Edenbridge, UK) filled with $3 \mathrm{M} \mathrm{NaCl}$ (5-15 M $\Omega$ ). For baseline recordings, slices were stimulated at $0.1 \mathrm{~Hz}$ for $20 \mathrm{~min}$ at stimulation intensities of $40-80 \mu \mathrm{A}$. To induce LTD, a $1 \mathrm{~Hz}$ stimulus train was delivered for $15 \mathrm{~min}$ (900 stimuli) at baseline stimulus intensity. LTP was induced by applying theta burst stimulation (TBS; three bursts, $10 \mathrm{~s}$ interburst interval, 10 trains, four pulses) or tetanic stimulation $(0.2 \mathrm{~ms}$ pulses at $100 \mathrm{~Hz}$ for $1 \mathrm{~s}$ ). Data were sampled at $5 \mathrm{kHz}$ on a personal computer using Labview (National Instruments, Munich, Germany). Input-output curves were constructed by averaging three consecutive fEPSPs evoked at each stimulus strength, and the amplitude of the presynaptic volley was plotted against the corresponding slope of the fEPSP. For each slice, we calculated the average of the normalized fiber volley (FV) amplitude corresponding to each class of fEPSP slope. With the exception of the first set of five slices (see Fig. 5A), the analysis of the data was done by the investigator blind to the genotype of the animals. Groups were compared with the $t$ test.

Whole-cell recording. Synaptic responses were recorded from transverse hippocampal slices ( $400 \mu \mathrm{m}$ thick) of 2- to 3-week-old mice. Perfusion medium contained the following (in $\mathrm{mm}$ ): $119 \mathrm{NaCl}, 2.5 \mathrm{KCl}, 4$ $\mathrm{CaCl}_{2}, 1.3 \mathrm{MgSO}_{4} 2.7 \mathrm{MgCl}_{2}, 1 \mathrm{NaH}_{2} \mathrm{PO}_{4}, 26 \mathrm{NaHCO}_{3}$, and 11 glucose, saturated with $95 \% \mathrm{O}_{2} / 5 \% \mathrm{CO}_{2}$ (carbogen). Slices were equilibrated in gassed $\mathrm{ACSF}$ at $32^{\circ} \mathrm{C}$ for at least $45 \mathrm{~min}$. All experiments were performed at room temperature $\left(22-24^{\circ} \mathrm{C}\right)$. Pyramidal CA1 neurons were visualized using differential interference contrast infrared video microscopy. All experiments were performed in the presence of $100 \mu \mathrm{M}$ picrotoxin (PTX).

Synaptic measurements of the AMPA/NMDA ratio were performed with 3-5 $\mathrm{M} \Omega$ glass electrodes filled with an internal solution consisting of 

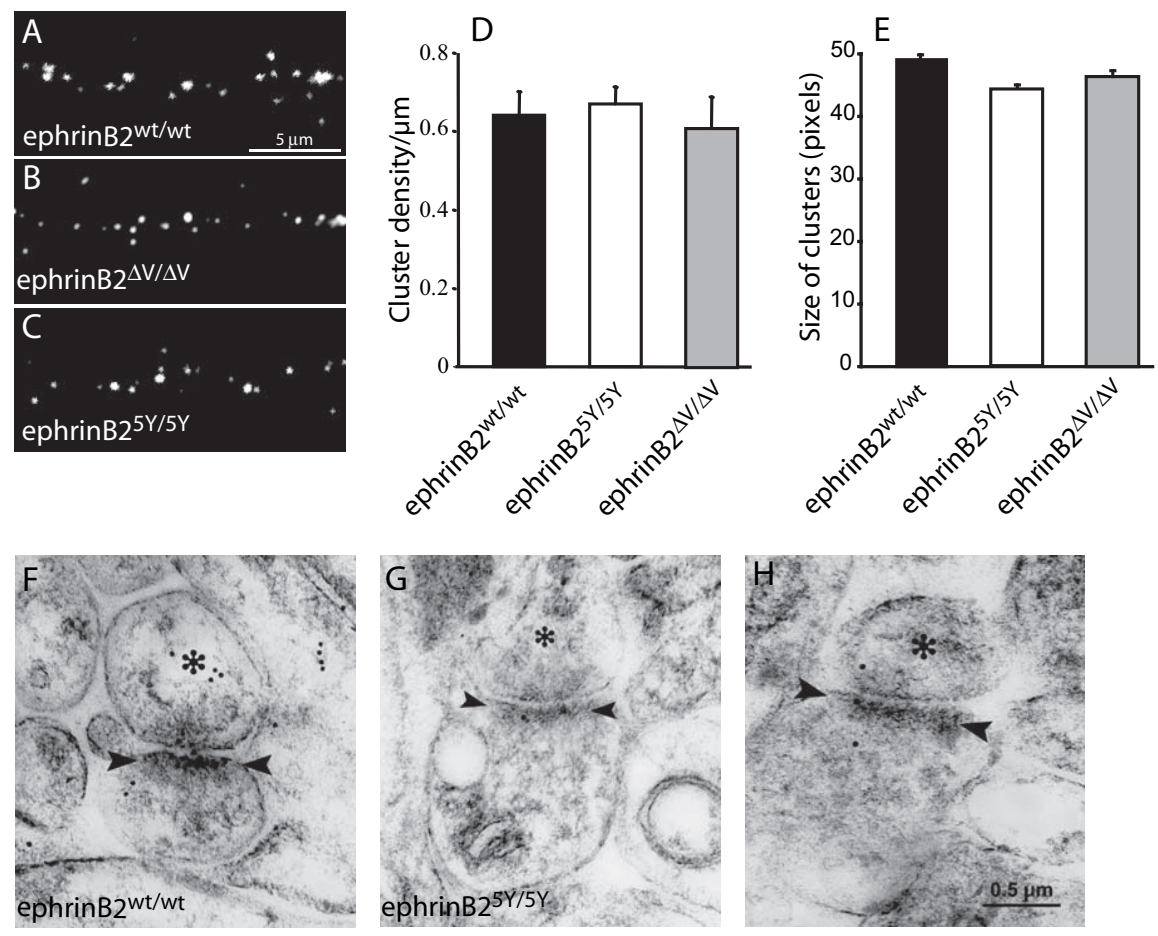

I
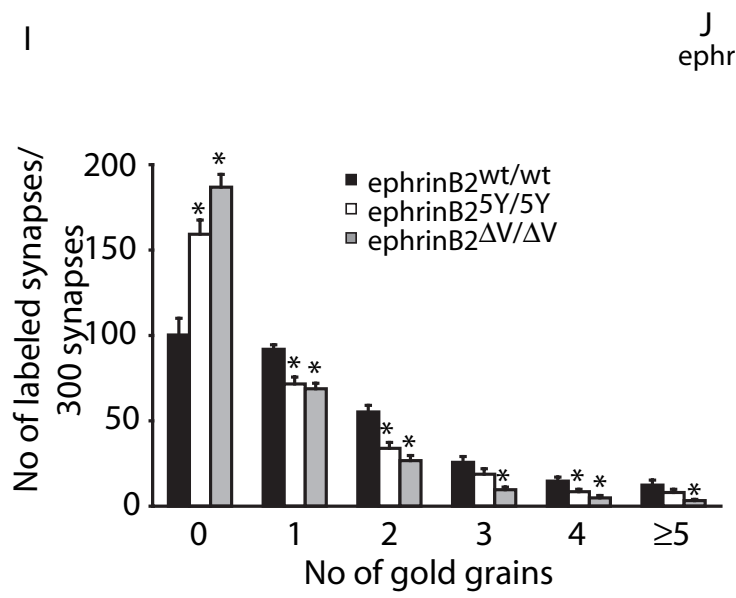

L

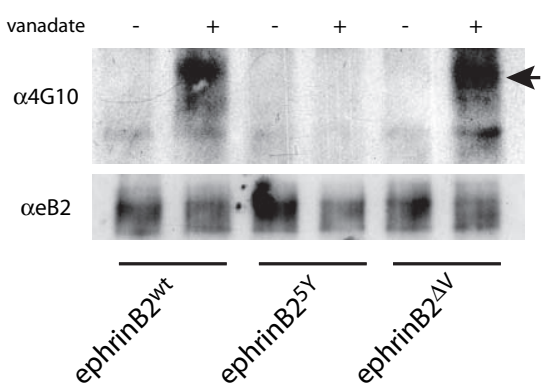

(mM) 150 CsGluconate, $8 \mathrm{NaCl}, 2 \mathrm{MgATP}, 10$ HEPES, 0.2 EGTA, and 5 QX314 [ $N$-(2,6-dimethylphenylcarbamoylmethyl)-triethylammonium bromide], $\mathrm{pH}$ 7.2. Ratios of NMDA to AMPA currents in CA1 pyramidal cells were obtained by evoking EPSCs with a monopolar glass electrode. AMPA EPSCs were recorded at $-70 \mathrm{mV}$, the NMDA component was recorded at +40 $\mathrm{mV}$, and the current was taken $70 \mathrm{~ms}$ after stimulus. Paired-pulse facilitation (PPF) was determined as the ratio of the second AMPA EPSC to the first AMPA EPSC at an interstimulus interval of $40 \mathrm{~ms}$. Miniature EPSCs (mEPSCs) were recorded at $-70 \mathrm{mV}$ in ACSF supplemented with tetrodotoxin $(0.5 \mu \mathrm{M})$, PTX $(100 \mu \mathrm{M})$, and tetrachloromethane $(250 \mu \mathrm{M})$ to increase the frequency of events. mEPSCs were analyzed off-line with customized software using a threshold of $5 \mathrm{pA}$.

\section{Results}

Expression and characterization of mutant isoforms of ephrinB2

In a previous communication (Makinen et al., 2005), we had shown that mutant ephrinB2 ${ }^{5 Y}$ and ephrinB2 ${ }^{\Delta V}$ isoforms were expressed at equal levels in adult brain lysates, were tyrosine phosphorylated to similar degrees in embryo protein lysates, and were expressed on the cell surface of transfected cells at similar levels compared with wild-type ephrinB2. Although this was strong evidence for normal subcellular targeting of mutant ephrinB2 protein, we now investigated surface expression and clustering behavior of endogenous ephrinB2 in cultured neurons. Hippocampal neuron cultures were established from control homozygous knock-in embryos (at E16.5) expressing wild-type ephrinB2 (ephrinB2 $2^{W T / W T}$ ), or mutant ephrinB2 isoforms (ephrinB2 $2^{5 Y / 5 Y}$ and ephrinB2 $\left.2^{\Delta V / \Delta V}\right)$. After 2 DIV, we used soluble EphB4-Fc fusion protein to specifically induce ephrinB2 protein clusters. In the presence of control Fc protein, no ephrinB2 clusters were induced (data not shown). Endogenous ephrinB2 protein

$\leftarrow$

anti-GRIP antibodies to visualize the levels of GRIP in the cells (bottom). Note that GRIP is not coimmunoprecipitated with ephrinB2 ${ }^{\Delta v}$. $\boldsymbol{K}$, Quantification of ephrinB2 (eB2) coimmunoprecipitation with GRIP1 [ratio between GRIP and eB2 optical density (OD)]. $\boldsymbol{L}$, Tyrosine phosphorylation of mutant ephrinB2 proteins in adult hippocampal slices. Slices derived from ephrinB2 ${ }^{\text {WT/WT }}$ control, ephrinB2 ${ }^{5 Y / 5 Y}$, and ephrin $B 2^{\Delta V / \Delta V}$ mice were either left unstimulated or were stimulated with the general protein tyrosine phosphatase inhibitor orthovanadate. Slices were lysed, and ephrinB2 was immunoprecipitated using anti-ephrinB2 antibodies. The proteins were immunoblotted with either anti-ephrinB2 (bottom) or anti-phosphotyrosine (4G10; top) antibodies. The arrow points to ephrinB2. Error bars indicate SEM. 
clusters were visualized by staining against the Fc portion of EphB4-Fc and quantified using MetaMorph software. We did not detect any marked differences in the densities and sizes of ephrinB2 clusters in neurons expressing the mutant ephrinB2 isoforms compared with wild-type knock-in ephrinB2 (Fig. 1A-E). Staining of ephrinB2 conditional knock-outs [ephrinB2Nestincre (Grunwald et al., 2004)] with EphB4-Fc did not reveal fluorescent clusters, indicating specific binding to ephrinB2 (supplemental Fig. S1, available at www.jneurosci.org as supplemental material). These findings suggest that the majority of ephrinB2 mutant proteins were transported to the appropriate subcellular locations in hippocampal neurites. To directly visualize endogenous ephrinB2 at the CA3-CA1 synapse, we applied immunoelectron microscopic analysis using a specific ephrinB2 antibody (Fig. $1 F-H$ ). Using this technique, we had previously shown that ephrinB2 labeling at the postsynaptic side dropped nearly fourfold in ephrinB2 conditional knock-outs (ephrinB2-CamKIIcre) (Grunwald et al., 2004). Here, we found that the numbers of gold particles at ephrinB2-positive synapses and the number of labeled synapses were lower in the mutants than in the controls (Fig. 1I). Together with the results from previous work (Makinen et al., 2005), these data suggest that targeting of ephrinB2 to subcellular sites was mainly unaffected in the ephrinB2 $2^{5 Y / 5 Y}$ and ephrinB2 $2^{\Delta V / \Delta V}$ mice (see Discussion).

To evaluate PDZ binding by mutant ephrinB2 proteins, we investigated the interaction with GRIP1, a seven-PDZ domaincontaining protein enriched at excitatory synapses (Dong et al., 1997) and likely to interact with ephrinB2 (Bruckner et al., 1999; Lin et al., 1999). We expressed ephrinB2 isoforms in HeLa cells and compared relative protein levels by Western blot analysis against GFP, which was attached to their extreme $\mathrm{N}$ terminus, a modification that does not interfere with surface expression and receptor binding (Zimmer et al., 2003; Makinen et al., 2005) (Fig. $1 J)$. EphrinB2 ${ }^{\mathrm{WT}}$ and ephrinB2 ${ }^{5 \mathrm{Y}}$ isoforms coimmunoprecipitated with GRIP1, demonstrating that PDZ domain-dependent binding of GRIP1 was unaffected by the removal of tyrosine residues in ephrinB2. In contrast, GRIP1 was not detected in ephrinB2 ${ }^{\Delta \mathrm{V}}$ immunoprecipitates, indicating that PDZ binding of GRIP1 was destroyed [as shown previously for syntenin (Makinen et al., 2005)]. Quantification of six separate experiments revealed that the ability of ephrinB2 ${ }^{\Delta \mathrm{V}}$ to coimmunoprecipitate GRIP was 10-fold lower compared with ephrinB2 ${ }^{\mathrm{WT}}$ and ephrinB2 ${ }^{5 Y}$ isoforms (Fig. $1 K$ ). To assess tyrosine phosphorylation of endogenous ephrinB2 isoforms in acute hippocampal slices of adult mice, we treated the slices with the tyrosine phosphatase inhibitor vanadate to allow maximum tyrosine kinase activity. In the presence of vanadate, the ephrinB2 ${ }^{\Delta \mathrm{V}}$ protein was tyrosine phosphorylated to a similar extent as wild-type ephrinB2, suggesting that it can be a substrate for tyrosine kinases in adult hippocampus (Fig. $1 L$ ). As expected, the mutant ephrinB2 ${ }^{5 Y}$ isoform failed to get tyrosine phosphorylated under indicate SEM.
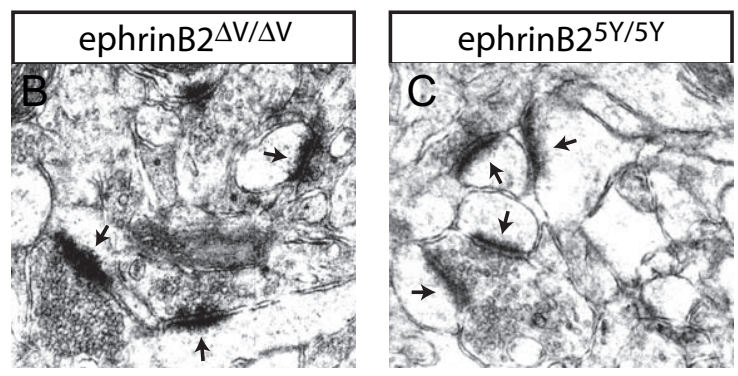

$\mathrm{E}$

$\mathrm{F}$
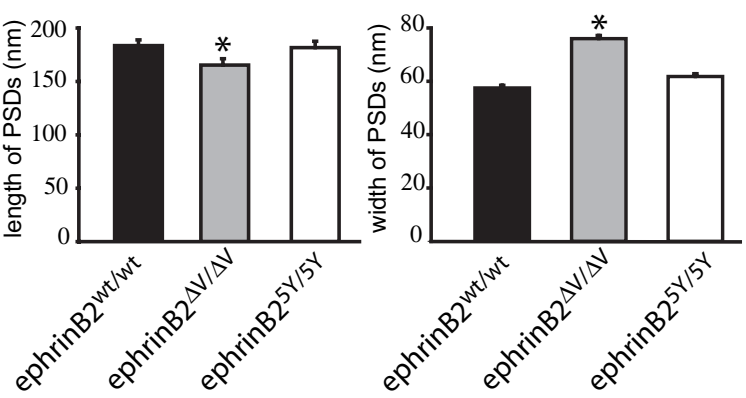

ep

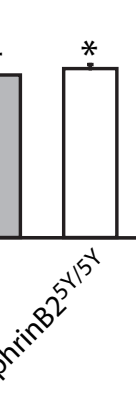

$e^{k} \quad e^{p}$

Figure 2. Morphologies of synapses derived from ephrinB2 mutant mice. A-C, Electron micrographs showing the morphology synapses per $100 \mu \mathrm{m}^{2}$ in the CA1 region ( $n=3$ mice per genotype; $>2000$ synapses per animal counted) of 2-month-old mice.

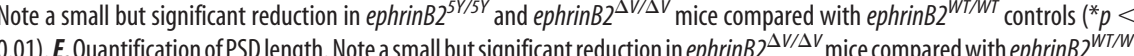
controls $\left({ }^{*} p<0.01\right)$ and no changes in ephrinB2 $2^{5 Y / 5 Y}$ mice. $\boldsymbol{F}$, Quantification of PSD width. Note a small but significant increase in ephrinB2 ${ }^{\Delta V / \Delta V}$ mice compared with ephrinB2 ${ }^{W T / W T}$ controls $\left({ }^{*} p<0.01\right)$ and no changes in ephrinB2 $2^{5 Y / 5 Y}$ mice. Error bars

these conditions (Fig. $1 \mathrm{~L}$ ). These results also confirmed that the overall levels of ephrinB2 proteins in the adult mutant hippocampus were normal in the knock-in mutants. Together, these findings indicate that mutant ephrinB2 proteins are targeted to correct subcellular sites and behave as expected with respect to PDZ domain-dependent binding and susceptibility to tyrosine phosphorylation.

\section{Normal ultrastructural morphology of ephrinB2 $2^{5 Y / 5 Y}$ mice}

Previous reports had indicated that the neuronal receptors for ephrinB2, namely EphB1-B3 and EphA4, have (partially redundant) functions in the formation of synapses and spines (Dalva et al., 2000; Henkemeyer et al., 2003; Murai et al., 2003; Kayser et al., 2006). In EM analyses of ephrinB2 conditional knock-outs, we had previously not found differences in CA1 synapse numbers compared with littermate controls (Grunwald et al., 2004). Because the ephrinB2 isoform knock-ins are nonconditional and mutant ephrinB2 proteins are present throughout development, it is possible that effects on synapse number occur that are not seen in conditional knock-outs. We therefore quantified the numbers of synapses in the CA1 region and assessed the morphology of PSDs. We found a modest, yet significant, reduction in CA1 synapse numbers in both ephrinB2 knock-in mutants compared with ephrinB2 $2^{W T / W T}$ controls (20\% for ephrinB2 $2^{\Delta V / \Delta V}$ and $15 \%$ for ephrinB2 $2^{5 Y / 5 Y}$ at 6 weeks of age) (Fig. $2 A-D$ ). This reduction in synapse numbers was milder at postnatal day 15 (P15; 14\% for ephrinB2 $2^{\Delta V / \Delta V}$ and $10 \%$ for ephrinB2 $2^{5 Y / 5 Y}$ ) (supplemental Fig. S2, available at www.jneurosci.org as supplemental material). A previous report had indicated a modest reduction of PSD length in CA1 and CA3 regions of triple EphB knock-out 

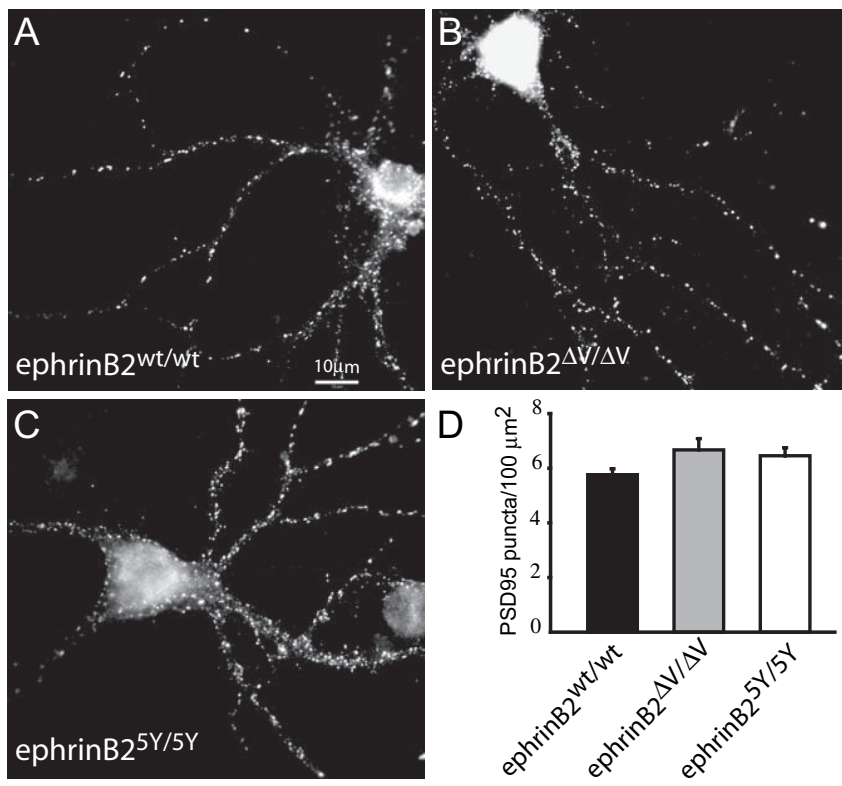

Figure 3. Fluorescence analysis of PSD-95 puncta in cultured hippocampal neurons. $\boldsymbol{A}-\boldsymbol{C}$ Representative images of cells were derived from E16.5 embryos of the indicated mouse lines, cultured for 20 DIV, and immunostained using anti-PSD-95 antibodies. D, Quantification of PSD-95 puncta per $100 \mu \mathrm{m}^{2}$. No significant differences were observed ( $n=3$ embryos and $90-130$ neurons per genotype; $p>0.05$ ). Error bars indicate SEM.

mice $\left(E p h B 1^{-/-} ; B 2^{-/-} ; B 3^{-/-}\right)$(Henkemeyer et al., 2003). We found a modest $(10 \%)$ decrease of PSD length in ephrinB2 $2^{\Delta V / \Delta V}$ but not in ephrinB2 $2^{5 Y / 5 Y}$ mice, compared with ephrinB2 $2^{W T / W T}$ controls (Fig. $2 E$ ). In addition we noticed a significant increase in PSD width in ephrinB2 $2^{\Delta V / \Delta V}$ but not in ephrinB2 ${ }^{5 Y / 5 Y}$ mice, compared with ephrinB2 $2^{W T / W T}$ controls (32 and 7\%, respectively) (Fig. $2 F$ ). The pattern of hippocampal dendrites in the stratum radiatum of the CA1 was similar based on MAP2 staining in all three lines (supplemental Fig. S3, available at www.jneurosci.org as supplemental material).

Because ephrinB2 is predominantly localized postsynaptically at CA3-CA1 synapses, we next asked whether the modification of the cytoplasmic domain of ephrinB2 would alter the number of postsynaptic specializations in vitro. We cultured hippocampal neurons from ephrinB2 mutants (as described for Fig. 1) and visualized postsynaptic PSD-95-immunoreactive puncta by immunofluorescence after 20 DIV. We found no significant differences in the numbers of PSD-95-positive puncta between ephrinB2 mutants and ephrinB2 $2^{W T / W T}$ controls (Fig. 3). Together, these results suggest that the mutant ephrinB2 protein lacking all tyrosine residues (ephrinB2 ${ }^{5 \mathrm{Y}}$ ) mediates normal synapse morphology in vivo and postsynaptic specializations in cultured neurons. Expression of the ephrinB2 ${ }^{\Delta \mathrm{V}}$ protein leads to a slightly altered synapse morphology but normal postsynaptic specializations in cultured neurons.

\section{Basal synaptic parameters are unchanged in ephrinB2 cytoplasmic mutants}

We next examined the functional consequences of the mutations in the ephrinB2 cytoplasmic domain. We performed a number of electrophysiological tests comparing ephrinB2 $2^{\Delta V / \Delta V}$ and ephrinB2 $2^{5 Y / 5 Y}$ mice to ephrinB2 $2^{W T / W T}$ controls, which did not show any significant differences to wild-type mice (data not shown). First, we compared basal synaptic transmission between ephrinB2 $2^{W T / W T}$ and mutant mice. fEPSPs were evoked with in- creasing stimulus intensities at CA1 synapses by stimulating Schaffer collaterals, one of the three main excitatory pathways. The sizes of the presynaptic FVs, which are proportional to the number of presynaptic axons recruited by the stimulation, were compared with the slope of the fEPSP response, to establish input-output relationships (Fig. $4 A$ ). We observed no differences between ephrinB2 $2^{W T / W T}$ and ephrinB2 $2^{\Delta V / \Delta V}$ or ephrinB2 $2^{5 Y / 5 Y}$ mice, respectively (ephrinB2 $2^{\Delta V / \Delta V}$ mice: slope and percentage of the control, $93 \pm 5.6 \%$; ephrinB2 $2^{5 Y / 5 Y}$ mice: slope and percentage of the control, $115 \pm 13.2 \% ; p>0.2, t$ test).

To address whether the numbers of synaptic AMPA and/or NMDA receptors were different in mutant mice, we compared the sizes of AMPA receptor EPSCs with those of NMDA receptor EPSCs by whole-cell recordings of CA1 neurons in hippocampal slices. AMPA receptor EPSCs were evoked at a membrane potential of $-70 \mathrm{mV}$, and NMDA receptor EPSCs were evoked at +40 $\mathrm{mV}$ to relieve the magnesium block. The magnitude of the NMDA receptor EPSC was determined by measuring the amplitude of the EPSCs $70 \mathrm{~ms}$ after stimulus. For control neurons, the NMDA/AMPA ratio was $1.6 \pm 0.1(n=10)($ Fig. $4 B)$. The ratio of NMDA to AMPA was not significantly changed in the mutant mice (ephrinB2 $2^{\Delta V / \Delta V}: 1.7 \pm 0.3, n=11$; ephrinB2 $2^{5 Y / 5 Y}: 1.8 \pm 0.2$, $n=9 ; p>0.05, t$ test $)$.

Next, we measured PPF, a sensitive measure of changes in the probability of transmitter release (Pr). To evaluate the effects of ephrinB2 cytoplasmic domain mutations on the $\mathrm{Pr}$, we measured PPF using the ratios of the second and the first EPSP slopes at an interpulse interval of $40 \mathrm{~ms}$. As shown in Figure $4 C$, we found that synapses in wild-type and mutant mice exhibited very similar PPFs during basal synaptic transmission. These results indicate that presynaptic functions in these mice were normal.

Finally, we designed experiments to look for changes in functional synapse numbers. The amplitude of mEPSCs is a measure for the AMPA receptor number per synapse, whereas a change in mEPSC frequency reflects a change in the number of functional synapses. Comparison of the cumulative EPSC amplitudes and frequencies (Fig. 4D) for the wild-type and the mutant mice revealed no significant differences. mEPSC frequencies were measured in 2- to 3-week-old mice, at a time when electron microscopy revealed mild reductions in synapse numbers (14\% for ephrinB2 $2^{\Delta V / \Delta V}$ and $10 \%$ for ephrinB2 $2^{5 Y / 5 Y}$ mice). Because various parameters of mEPSC (such as probability of spontaneous vesicle fusion, detection level, attenuation in the dendrite) are heterogeneous from synapse to synapse, it is not surprising that small changes in synapse number are not detected as a change in mEPSC frequency. Together, these findings indicate that the ephrinB2 cytoplasmic domain mutations caused no apparent changes in excitatory circuitry.

\section{EphrinB2-PDZ interaction and tyrosine phosphorylation sites participate in CA3-CA1 hippocampal LTP}

Using two different protocols to induce LTP (tetanic and theta burst; see Materials and Methods), we investigated the consequences of ephrinB2 cytoplasmic domain mutations in CA3CA1 hippocampal LTP. Using acute slices from adult mice, either tetanic stimulation (Fig. 5A) or TBS (Fig. 5B) were applied to fibers of the CA3 presynaptic neurons, and LTP was recorded from CA1 neurons for up to $1 \mathrm{~h}$ after stimulation. In both stimulation protocols, the magnitude of the potentiation was different between controls and mutants. After tetanic stimulation (Fig. $5 A$ ), the mean EPSP slope as a percentage of baseline 55-60 min after stimulation was $156.4 \pm 6.9 \%$ in the ephrinB2 $2^{W T / W T}$ controls $(n=13$ slices $)$, whereas ephrinB $2^{\Delta V / \Delta V}$ and ephrinB2 $2^{5 Y / 5 Y}$ 
A

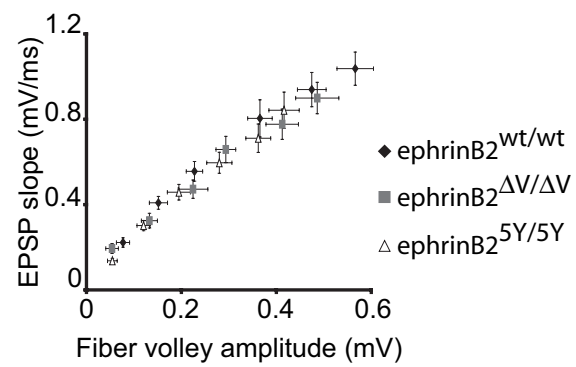

B

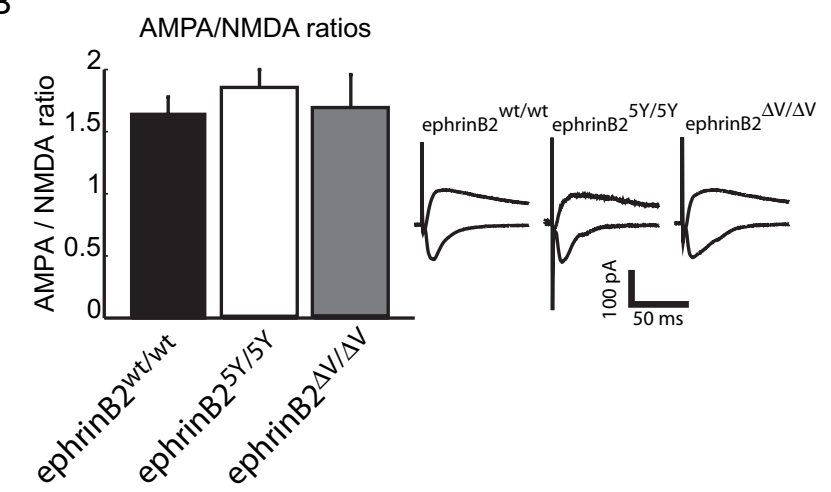

C

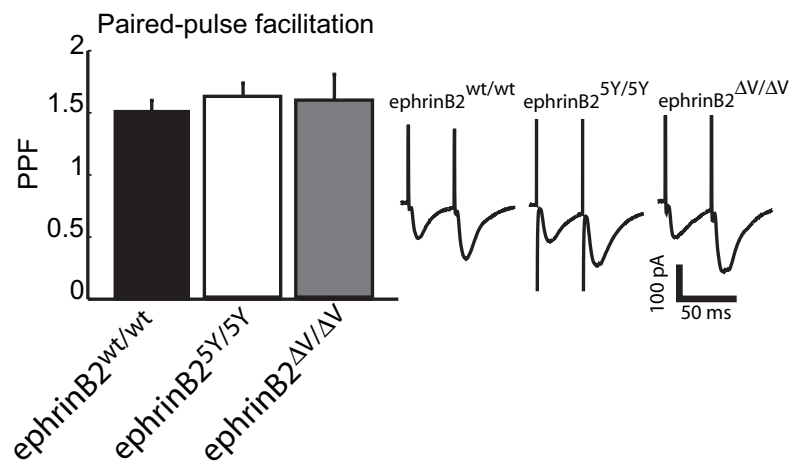

D
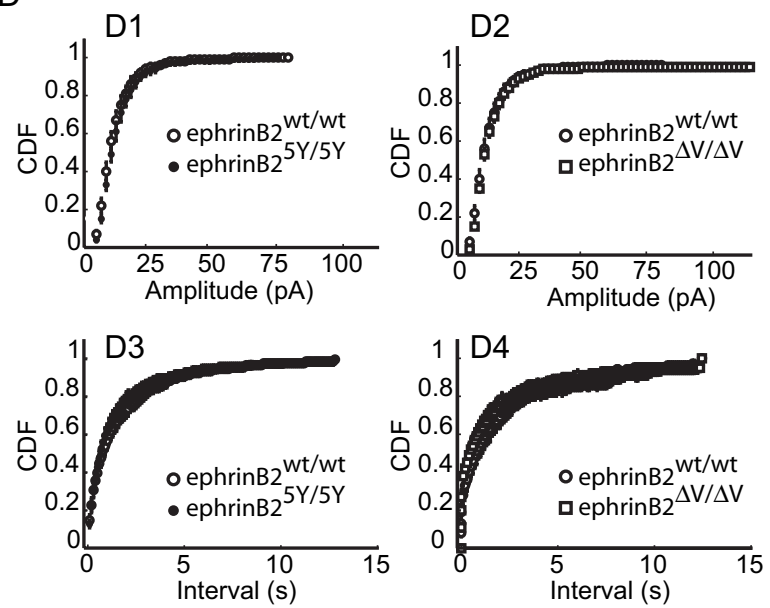

Figure 4. Basal synaptic parameters are unchanged in ephrinB2 cytoplasmic mutants. $\boldsymbol{A}$, $\mathrm{fEPSP}$ slope at various stimulus intensities (FV). In the range of $0.1-0.6 \mathrm{mV}$, the three groups of mice showed similar values (ephrinB2 ${ }^{W T / W T}, n=17$ slices; ephrinB2 $2^{\Delta V / \Delta V}, n=15$ slices; ephrinB $2^{5 Y / 5 Y}, n=19$ slices; $p>0.05, t$ test). $\boldsymbol{B}, \mathrm{NMDA} /$ AMPA ratio. AMPA receptor EPSCs were evoked at a membrane potential of $-70 \mathrm{mV}$, and NMDA receptor EPSCs were evoked at +40 $\mathrm{mV}$. For control neurons, the NMDA/AMPA ratio was $1.6 \pm 0.1$ ( $n=10$ slices). The ratio of NMDA to AMPA was not significantly changed in the mutant mice (ephrinB2 $2^{\Delta V / \Delta V}: 1.7 \pm 0.3$, mice showed significantly lower normalized slopes (117.7 \pm 3.8 and $120.6 \pm 8.9 \%$, respectively; $p<0.01, t$ test). Similar differences were observed after TBS (Fig. $5 B$ ), indicating that the impairments in LTP were not specific to a single induction protocol. We next investigated slices taken from P14-P20 animals. As shown in Figure $5 C$, both ephrinB2 ${ }^{\Delta V / \Delta V}$ and ephrinB2 $2^{5 Y / 5 Y}$ mice displayed reduced LTP compared with ephrinB2 ${ }^{W T / W T}$ controls, although the difference was less dramatic than in adult slices (ephrinB2 $2^{W T / W T}, 141.5 \pm 5.7 \%$; ephrinB2 $2^{\Delta V / \Delta V}, 120.8 \pm 5.5 \%$; ephrinB2 $2^{5 Y / 5 Y}, 120.9 \pm 4.6 \% ; p<0.01, t$ test). These data indicate that hippocampal LTP requires both intact PDZ target and tyrosine phosphorylation sites in the ephrinB2 cytoplasmic domain.

EphrinB2 tyrosine phosphorylation sites are not required for LTD and depotentiation

Because LTD at CA3-CA1 hippocampal synapses requires the presence of ephrinB2 (Grunwald et al., 2004), we analyzed hippocampal LTD in slices taken from ephrinB2 ${ }^{W T / W T}$ control knock-in mice and ephrinB2 signaling mutants. After recording stable baseline responses (see Materials and Methods), LTD was induced by low-frequency stimulation (LFS) of 900 stimuli at 1 $\mathrm{Hz}(15 \mathrm{~min})$. As shown in Figure $6 \mathrm{~A}$, ephrinB2 ${ }^{W T / W T}$ controls showed a persistent decrease in fEPSPs, which lasted for at least 60 min. EphrinB2 $2^{\Delta V / \Delta V}$ slices were defective in LTD and returned to baseline at $40 \mathrm{~min}$ after LTD induction (ephrinB2 ${ }^{\Delta V / \Delta V}$ slices, $97.9 \pm$ $2.2 \%$ vs ephrinB2 $2^{W T / W T}$ slices, $84.1 \pm 1.7 \%$; $p<0.01, t$ test). Unexpectedly, ephrin $B 2^{5 Y / 5 Y}$ slices showed LTD nearly indistinguishable from ephrinB2 ${ }^{W T / W T}$ controls (ephrinB2 $2^{5 Y / 5 Y}, 82.3 \pm 3.4 \%$ vs ephrinB2 ${ }^{W T / W T}$ slices, $84.1 \pm 1.7 \% ; p=0.56, t$ test).

We additionally analyzed another form of long-term plasticity known as depotentiation, the depression of synaptic efficacy at synapses that have recently undergone LTP (O'Dell and Kandel, 1994). Although the induction protocol for depotentiation is identical to LTD, they may represent distinct processes (Montgomery and Madison, 2002, and references within). After recording a stable baseline, we applied a tetanic stimulation to induce LTP, followed (after $10 \mathrm{~min}$ ) by a depotentiation stimulus (LFS of 900 stimuli at $1 \mathrm{~Hz}$ for $15 \mathrm{~min}$ ). Slices derived from ephrinB $2^{W T / W T}$ controls showed a normal initiation phase of LTP (first 10 min after tetanus application) and complete depotentiation after 15 min of LFS (Fig. 6B). As expected from the LTP

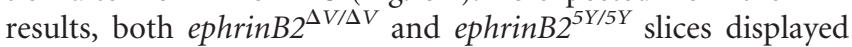
reduced early LTP, but their reaction to LFS varied: ephrinB2 $2^{\Delta V / \Delta V}$ slices were defective in depotentiation and remained potentiated 55-60 min after LFS application (fEPSP slope size: ephrinB2 $2^{\Delta V / \Delta V}$ slices, $126.9 \pm 4.6 \%$ vs ephrinB2 $2^{W T / W T}$ slices, $104.0 \% \pm 7.7 \% ; p<0.05, t$ test). In contrast, ephrinB2 $2^{5 Y / 5 Y}$ slices displayed complete depotentiation $1 \mathrm{~h}$ after the application of the LFS protocol (98.9 $\pm 6.2 \%$ fEPSP slope) (Fig. $6 B$ ), following a time course indistinguishable from controls. These findings

$\leftarrow$

$n=11$ slices; ephrinB2 ${ }^{5 Y / 5 Y}: 1.8 \pm 0.2, n=9$ slices; $p>0.05, t$ test). C, PPF of the EPSP at an interstimulus interval (ISI) of $40 \mathrm{~ms}$ from the three groups of mice was not significantly different (ephrinB2 ${ }^{W T / W T}: 1.5 \pm 0.1, n=9$ slices; ephrinB2 ${ }^{\Delta V / \Delta V}: 1.6 \pm 0.2, n=9$ slices; ephrinB2 ${ }^{\text {YV/5Y }}$ : $1.6 \pm 0.1, n=8$ slices; $p>0.05, t$ test). $D$, Cumulative probability plot of the mEPSC amplitudes $(\boldsymbol{D 1}, \mathbf{D 2})$ and frequencies $(\mathbf{D} 3, \mathbf{D} 4)$ in the control and mutant mice. Neither mEPSC amplitudes nor mEPSC frequencies changed significantly in the mutant mice ( $\mathrm{AV}_{50}$ amplitude for mEPSCs: ephrinB2 $2^{W T / W T},-13.3 \pm 0.9 \mathrm{pA}, n=19$ slices; ephrinB2 ${ }^{5 Y / 5 Y},-14.4 \pm 0.8 \mathrm{pA}$, $n=19$ slices; ephrinB2 $2^{\Delta V / \Delta V},-14.2 \pm 4 \mathrm{pA}, n=18$ slices; $p>0.05, t$ test; frequency of events: ephrinB2 ${ }^{\text {WT } / W T}, 0.9 \pm 0.2 \mathrm{~Hz}, n=19$ slices; ephrinB2 ${ }^{5 / 5 Y}, 1.0 \pm 0.2 \mathrm{~Hz}, n=19$ slices; ephrinB2 ${ }^{\Delta V / \Delta V}, 1.0 \pm 0.2 \mathrm{~Hz}, n=18$ slices; $p>0.05, t$ test). Error bars indicate SEM. 
A
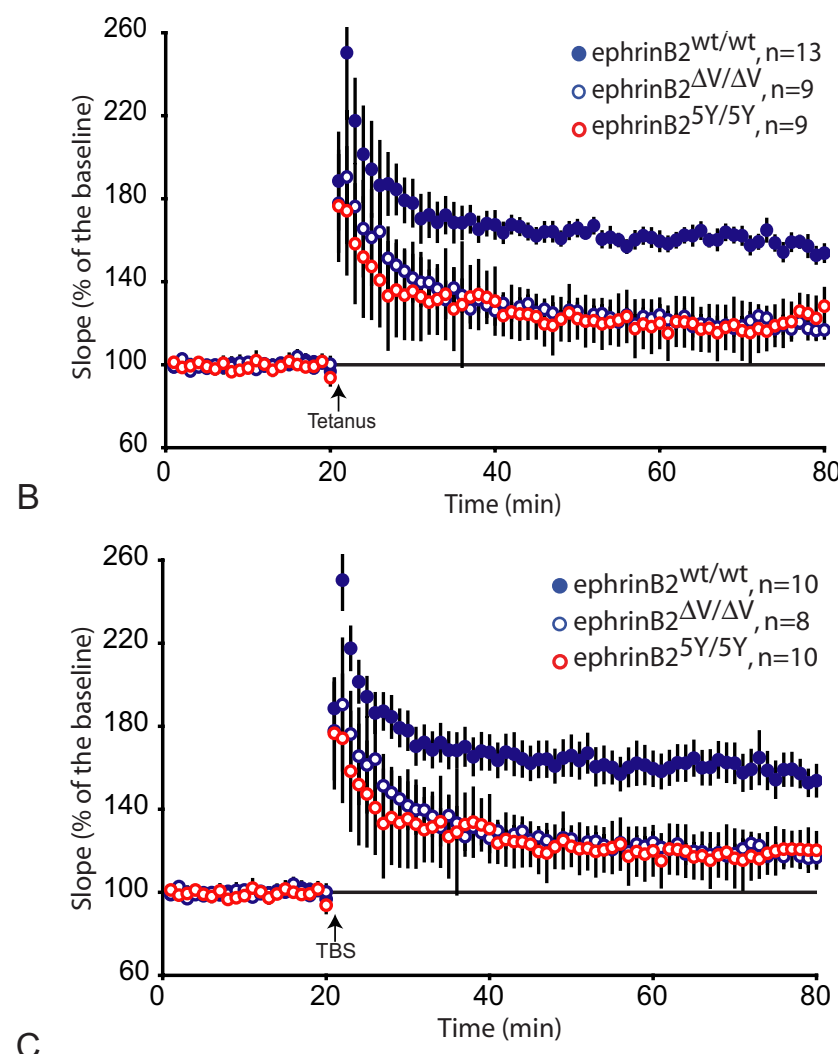

C

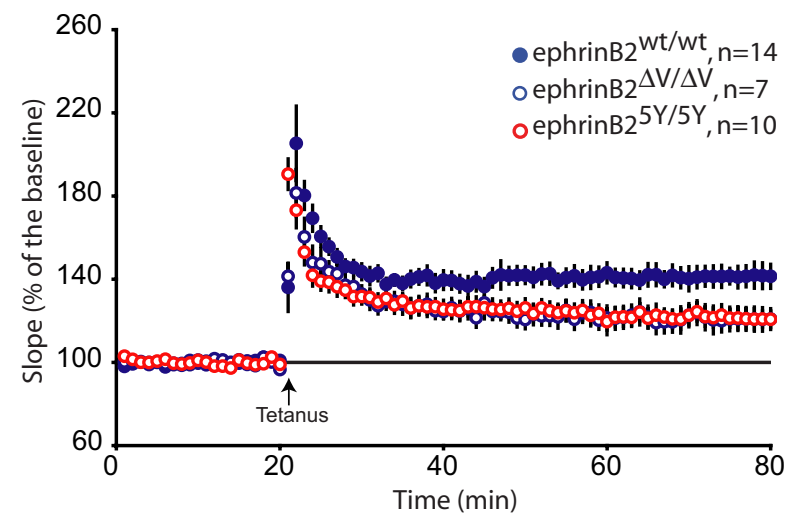

Figure 5. EphrinB2-PDZ interaction and tyrosine phosphorylation sites are critical for LTP. $A$, LTP was induced by stimulation of presynaptic CA3 neurons with tetanus. Adult ephrinB2 mutant mice showed a strong deficit in CA3-CA1 LTP compared with controls $(117.7 \pm 3.8 \%$ in ephrinB2 $2^{\Delta V / \Delta V}$ and $120 \pm 8.9 \%$ in ephrinB2 $2^{5 Y / 5 Y}$ mutants vs $156 \pm 6.9 \%$ in ephrinB2 ${ }^{\text {WT/WT }}$ controls at $55-60$ min after tetanus; $p<0.05$ ). $B$, LTP was induced by TBS. Adult ephrinB2 mutant mice showed a deficit in CA3-CA1 LTP compared with controls $(130.3 \pm 4.8 \%$ in ephrinB2 $2^{\Delta V / \Delta V}$ and $135.3 \pm 5.9 \%$ inn ephrinB2 $2^{5 Y / 5 Y}$ mutants vs $157.5 \pm 8 \%$ in ephrinB2 ${ }^{\text {WT } W T}$ controls at $55-60$ min after tetanus; $p<0.05$ ). C, LTP was induced in young hippocampal slices (P14-P20) by tetanus. Slices derived from young ephrinB2 mutant mice showed a deficit in CA3-CA1 LTP compared with controls (120.8 $\pm 5.5 \%$ in ephrinB2 ${ }^{\Delta V / \Delta V}$ and $120.9 \pm 4.6 \%$ in ephrin $B 2^{5 Y / 5 Y}$ mutants vs $141.5 \pm 5.7 \%$ in ephrinB $B 2^{\text {WT/WT }}$ controls at $55-60$ min after tetanus; $p<0.05)$.

suggest that the required function of ephrinB2 in LTD as well as in depotentiation is independent of phosphotyrosine signaling.

EphrinB2 reverse signaling in cultured neurons induces phosphorylation of NMDA receptors

In a number of different cell types, including excitatory neurons, ephrinB reverse signaling involves the rapid recruitment and ac-
A
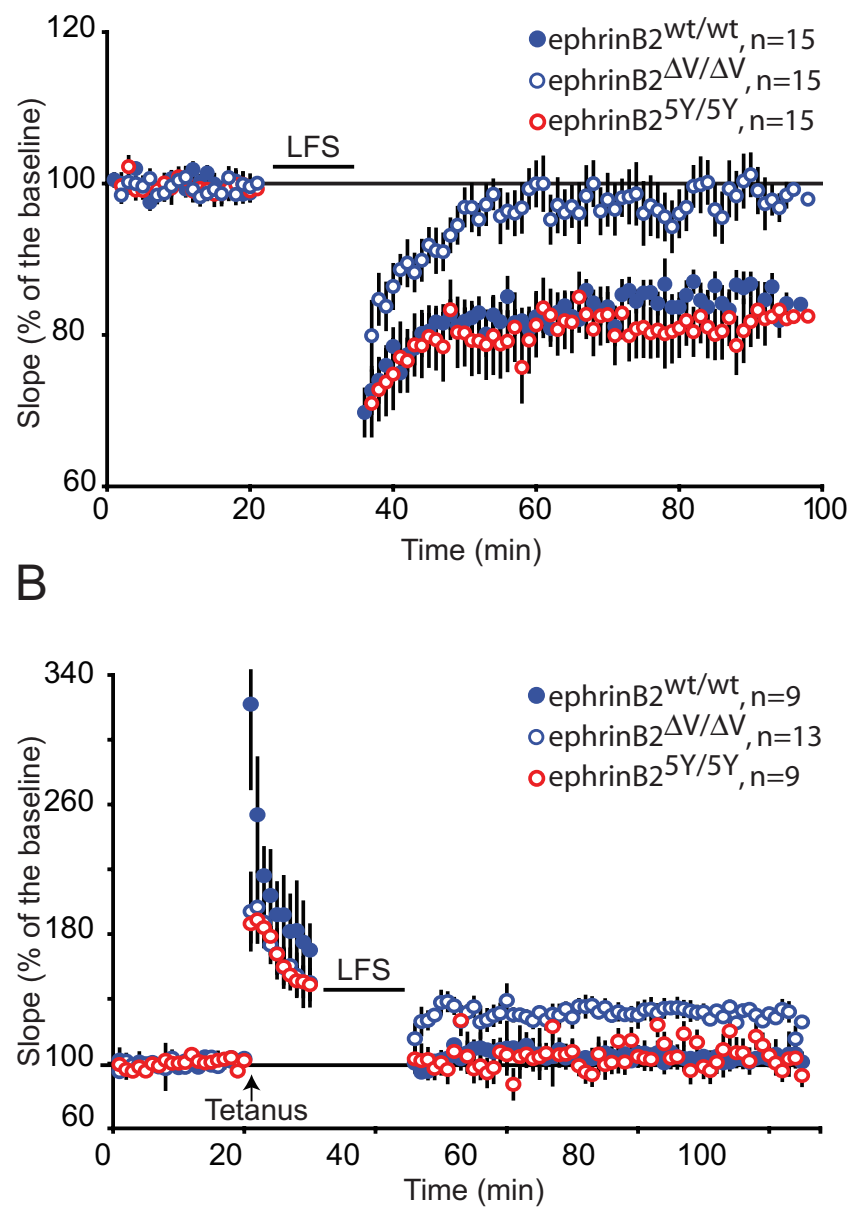

Figure 6. EphrinB2 tyrosine phosphorylation sites are not required for LTD and depotentiation. $A$, EphrinB2-PDZ interaction but not tyrosine phosphorylation sites are required for LTD in young hippocampal slices (P14-P20). LFS induced a significant long-lasting decrease in fEPSPs in ephrinB2 ${ }^{W T / W T}$ control and ephrinB2 ${ }^{\Delta V / \Delta V}$ slices but not in ephrinB2 $2^{5 / / 5 Y}$ slices $(97.9 \pm 2.2 \%$ in ephrinB2 ${ }^{\Delta V / \Delta V}$ mutants compared with $82.3 \pm 3.4 \%$ in ephrinB2 $2^{5 Y / 5 Y}$ mutants and $84.1 \pm$ $1.7 \%$ in ephrinB2 ${ }^{W T / W T}$ controls at $55-60$ min after LFS; $p<0.05$ ). $B$, Depotentiation is impaired in ephrinB2 $2^{\Delta V / \Delta V}$ but not ephrinB2 $2^{5 Y / S Y}$ mutants. Ten minutes after tetanus (arrow) to produce the initial phase of LTP, slices were subjected to a 15 min LFS train (horizontal line; 1 $\mathrm{Hz}$ ). The fEPSPs from ephrinB2 ${ }^{\text {WT/WT }}$ control and ephrinB2 $2^{5 Y / 5 Y}$ slices returned to baseline (ephrinB2 $^{\text {WT } / W T}$ slices, $104.0 \pm 7.6 \%$; ephrinB2 ${ }^{\text {YY/SY }}$ slices, $98.9 \pm 6.2 \%$ ), whereas ephrinB2 $2^{\Delta V / \Delta V}$ slices remained potentiated (126.9 $\pm 4.6 \% ; p<0.05$, compared with ephrinB2 $2^{\text {WT }}$ TT controls).

tivation of SFKs to ephrinB clusters (Palmer et al., 2002; Georgakopoulos et al., 2006). SFKs bind to the ephrinB cytoplasmic domain and phosphorylate ephrinB on tyrosine residues. SFKs are also the major protein tyrosine kinases that upregulate the activity of NMDA receptors (reviewed in (Salter and Kalia, 2004; Lee, 2006). SFK-mediated tyrosine phosphorylation of NMDA receptors is critical for induction of NMDA receptor-dependent LTP (Lu et al., 1998). Tyrosine phosphorylation of NMDA receptor subunits regulates their membrane trafficking. To begin addressing the biochemical events mediated by ephrinB2 reverse signaling, we investigated the degree of tyrosine phosphorylation of the NR2A subunit of NMDA receptors in cultured forebrain neurons. Stimulation of neurons derived from ephrinB2 ${ }^{W T / W T}$ mice with EphB4-Fc led to a robust increase in NR2A tyrosine phosphorylation compared with control Fc-treated cultures (Fig. $7 A-C)$. Interestingly, NR2A tyrosine phosphorylation was ab- 
normal in mutant neurons: in the presence of the ephrinB $2^{\Delta \mathrm{V}}$ isoform, basal NR2A tyrosine phosphorylation was elevated and was not further enhanced by EphB4-Fc stimulation (Fig. $7 B$ ). In the presence of the ephrinB2 ${ }^{5 Y}$ isoform, basal NR2A tyrosine phosphorylation was comparable to wildtype neurons, but EphB4-Fc stimulation did not lead to an increase in NR2A tyrosine phosphorylation. The changes in NR2A tyrosine phosphorylation correlated with similar changes in Src phosphorylation as revealed by a phospho-Src ELISA (Fig. 7D). These results demonstrate NR2A tyrosine phosphorylation as a consequence of ephrinB activation in cultured neurons and that both ephrinB2 ${ }^{\Delta \mathrm{V}}$ and ephrinB $2^{5 \mathrm{Y}}$ isoforms fail to regulate NR2A tyrosine phosphorylation.

\section{Discussion}

There is good evidence that ephrinB2 and the related ephrinB3 protein have cell autonomous and essentially nonredundant roles in activity-dependent plasticity in the postsynaptic CA1 neuron. At the CA3-CA1 synapse, receptors for ephrinB2 and ephrinB3, namely EphA4 and EphB2, function in a kinase-independent manner suggesting that these receptors do not act in the traditional sense as signaling receptors. They may act as ligands for ephrinBs competent for reverse signaling or may interact with other synaptic proteins such as NMDA receptors (Dalva et al., 2000; Grunwald et al., 2001, 2004; Henderson et al., 2001; Egea and Klein, 2007). EphrinB2 mRNA is 10 times more abundant in CA1 compared with CA3, and ephrinB2 immunoreactivity is found in the PSD of CA1 neurons. Finally, genetic ablation of ephrinB2 or ephrinB3 expression leads to defects in synaptic plasticity (Grunwald et al., 2004; Armstrong et al., 2006; Egea and Klein, 2007). In aggregate, these earlier observations suggest postsynaptic activation of ephrinB2 and of ephrinB3 are each critical for CA3-CA1 LTP.

The present study extends this concept by investigating the specific roles in synaptic plasticity of docking sites within the ephrinB2 cytoplasmic tail. We made two important observations. First, mice expressing ephrinB2 devoid of phosphorylatable tyrosine residues and therefore deficient in phosphotyrosinedependent signaling displayed strongly reduced hippocampal LTP to the level found in the absence of ephrinB2. Although the concept of ephrinB reverse signaling is well documented in vivo (Davy and Soriano, 2005), the relative importance of the phosphotyrosine-dependent mode of reverse signaling has remained unclear. The extremely mild lymphatic phenotype described for ephrinB2 $2^{5 Y / 5 Y}$ mice compared with the strong phenotypes seen in mutants with disrupted ephrinB-PDZ interactions (Davy et al., 2004; Makinen et al., 2005) had previously left unaddressed the necessary contributions of phosphotyrosinedependent ephrinB signaling (Makinen et al., 2005). The present work reemphasizes that tyrosine phosphorylation is an important component of ephrinB reverse signaling. Second, the required function of ephrinB2 in mechanisms of synaptic depression is independent of phosphotyrosine signaling. The differential requirement of intact tyrosine residues in ephrinB2
B

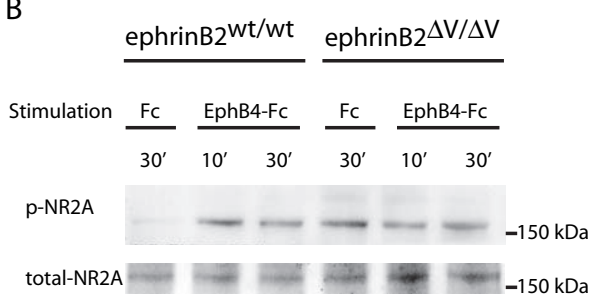

D

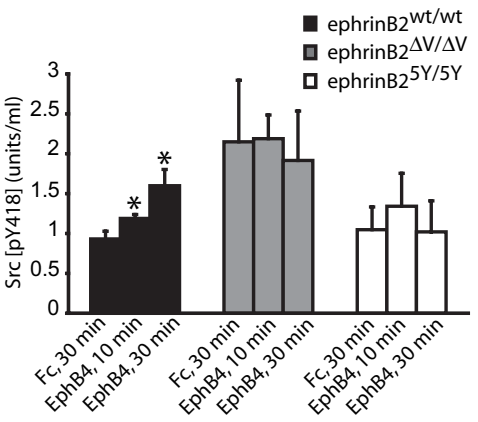

Figure 7. EphrinB2 activation causes NR2A and Src tyrosine phosphorylation. Dissociated cultures of embryonic forebrain (8 DIV) derived from wild-type $(\boldsymbol{A})$ or from the indicated mutant mice $(\boldsymbol{B}-\boldsymbol{D})$ were stimulated with control $\mathrm{Fc}$ or of Src phosphorylation at position 418, which is required for Src activation ( ${ }^{*} p<0.05, t$ test). Changes in Src phosphorylation observed in ephrinB2 $2^{\Delta V / \Delta V}$ and ephrinB2 ${ }^{Y Y / 5 Y}$ neurons were not significant. p-NR2A, Phosphorylated NR2A.

for two different forms of synaptic plasticity suggests that these point mutations affect reverse signaling rather than other cellular aspects of ephrinB2 biology such as subcellular trafficking or protein stability. Finally, EphB receptor-mediated forward signaling is not required for LTP (Grunwald et al., 2001, 2004); thus, it is likely that the synaptic deficiencies reported here reflect bona fide loss of ephrinB2 reverse signaling.

\section{Regulation of NMDA receptor function by tyrosine phosphorylation}

The results from cultured forebrain neurons indicate that tyrosine phosphorylation of NR2A is induced by activation of ephrinB2 reverse signaling. Because ephrinB2 reverse signaling activates SFKs (Fig. 7) (Palmer et al., 2002) and because SFKs mediate tyrosine phosphorylation of NR2A (Lu et al., 1998), our results are consistent with a model in which ephrinB2 triggers SFKmediated tyrosine phosphorylation of NR2A. Technical limitations have thus far prevented confirmation of such a model in acute hippocampal slices under LTP conditions. Tetanus stimulation generally activates only a small fraction of all excitatory synapses in CA1, and the degree of Src activation in cells under physiological conditions is generally not very high (less than twofold). It is possible that other protein tyrosine kinases unrelated to SFKs play a role in ephrinB2-mediated synaptic plasticity and that Eph forward signaling contributes to NMDA receptor tyrosine phosphorylation (Takasu et al., 2002). AMPA receptors are also phosphorylated by SFKs, and tyrosine phosphorylation of AMPA receptors affects their regulated internalization $(\mathrm{Ha}-$ yashi and Huganir, 2004). Hence, AMPA receptor tyrosine phosphorylation may contribute to stimulation-dependent LTP at excitatory synapses.

NR2A tyrosine phosphorylation appeared deregulated in cultured mutant neurons in different ways. In ephrinB2 $2^{\Delta V / \Delta V}$ neu- 
rons, basal NR2A tyrosine phosphorylation and Src phosphorylation were elevated and were not further increased by ephrinB2 activation. EphrinB2 coclustering with Src is sensitive to changes in membrane lipids (Palmer et al., 2002). In the absence of interactions with PDZ scaffolding proteins, ephrinB2 may be mislocalized in the synaptic membrane and form aberrant contacts with SFKs under basal conditions. In contrast, in ephrinB2 $2^{5 Y / 5 Y}$ neurons basal NR2A tyrosine phosphorylation and Src phosphorylation were normal but not increased by ephrinB2 activation. It is possible that ephrinB2 tyrosine phosphorylation is required for the assembly of a signaling complex that allows Src to access and phosphorylate NR2A receptors.

\section{How does the ephrinB $2^{5 Y}$ mutation affect LTP but not LTD?}

Both LTP and LTD require the activation of NMDA receptors. It is thought that the degree of NMDA receptor activation and the subsequent amount of calcium influx dictate the direction of change in long-term plasticity (Malenka and Nicoll, 1999). Partial inhibition of NMDA receptor function can change LTPinducing stimuli to produce LTD (Cummings et al., 1996). NMDA receptor subunits may also influence the direction of long-term plasticity. Inhibition of NR2A-containing NMDA receptors prevented the induction of LTP without affecting LTD, whereas inhibition of NR2B-containing receptors had the opposite effects (Liu et al., 2004). Recent results, however, demonstrated that activation of NR2B-containing NMDA receptors is not required for the induction of LTD in the hippocampus (Morishita et al., 2007). Interactions of NMDA receptors with their downstream signal transducers, such as CaMKII (calcium/ calmodulin-dependent protein kinase II), can also determine the degree of synaptic enhancement (Barria and Malinow, 2005). With the available tools, we cannot distinguish whether in ephrinB2 $2^{5 Y / 5 Y}$ slices NMDA receptor activation, subunit composition, or downstream signaling are affected to result in impairment of LTP but not LTD.

\section{Why is LTD affected in the ephrinB2 $2^{\Delta V / \Delta V}$ mutants?}

The interpretation of the phenotype of ephrin $B 2^{\Delta V / \Delta V}$ mice is somewhat more intricate than that of ephrinB2 $2^{5 Y / 5 Y}$ mice. We found subtle changes in PSD structure, namely increased PSD width and decreased length, in the ephrinB2 $2^{\Delta V / \Delta V}$ mice that correlate with the more severe changes in synaptic plasticity of these mutants (defective LTP and LTD) compared with the ephrinB2 $2^{5 Y / 5 Y}$ mice (normal LTD). We cannot exclude that the synaptic plasticity defects observed in those mice are related to the observed morphological changes. In contrast, basic synaptic transmission parameters (input/output, NMDA/AMPA receptor EPSCs, PPF, mEPSCs) were normal in ephrin B2 $2^{\Delta V / \Delta V}$ mice, suggesting that the observed alterations in synapse ultrastructure did not affect synaptic function. The electrophysiology results suggest that disrupted ephrinB2-PDZ interactions at the synapse contribute directly to the impairments in LTD. In case of the latter scenario, we would speculate that ephrinB2 is required to recruit essential PDZ proteins to excitatory synapses. It is known that interactions of AMPA receptors with PDZ proteins are essential for LTD (reviewed in (Derkach et al., 2007). GRIPs interact with GluR2 subunits of AMPA receptors and stabilize them at synaptic location (Dong et al., 1997; Osten et al., 2000). GRIPs also interact with ephrinBs, and the lack of ephrinB-GRIP interaction may affect activity-dependent AMPA receptor trafficking (C. L. Essmann, E. Martinez, J. Geiger, M. Zimmer, M. Traut, V. Stein, R. Klein, and A. Acker-Palmer, unpublished results).

\section{Conclusions}

Targeted mutations of docking sites in the ephrinB2 cytoplasmic tail have provided significant experimental advantages that allowed us to demonstrate an essential function for ephrinB tyrosine phosphorylation in synaptic plasticity. Our data suggest that different forms of synaptic plasticity require differential ephrinB2 reverse signaling: Whereas the induction of LTP requires a mechanism involving tyrosine phosphorylation of the ephrinB2 cytoplasmic tail, two forms of synaptic depression do not require similar mechanisms. Instead, ephrinB2-PDZ interactions seem necessary for LTD and depotentiation. Our findings provide the basis for additional investigations into the signaling pathways activated by ephrinB2 clusters at excitatory synapses.

\section{References}

Armstrong JN, Saganich MJ, Xu NJ, Henkemeyer M, Heinemann SF, Contractor A (2006) B-ephrin reverse signaling is required for NMDAindependent long-term potentiation of mossy fibers in the hippocampus. J Neurosci 26:3474-3481.

Artola A, Singer W (1993) Long-term depression of excitatory synaptic transmission and its relationship to long-term potentiation. Trends Neurosci 16:480-487.

Barria A, Malinow R (2005) NMDA receptor subunit composition controls synaptic plasticity by regulating binding to CaMKII. Neuron 48:289-301.

Bruckner K, Pablo Labrador J, Scheiffele P, Herb A, Seeburg PH, Klein R (1999) EphrinB ligands recruit GRIP family PDZ adaptor proteins into raft membrane microdomains. Neuron 22:511-524.

Calo L, Bruno V, Spinsanti P, Molinari G, Korkhov V, Esposito Z, Patane M, Melchiorri D, Freissmuth M, Nicoletti F (2005) Interactions between ephrin-B and metabotropic glutamate 1 receptors in brain tissue and cultured neurons. J Neurosci 25:2245-2254.

Contractor A, Rogers C, Maron C, Henkemeyer M, Swanson GT, Heinemann SF (2002) Trans-synaptic Eph receptor-ephrin signaling in hippocampal mossy fiber LTP. Science 296:1864-1869.

Cowan CA, Henkemeyer M (2001) The SH2/SH3 adaptor Grb4 transduces B-ephrin reverse signals. Nature 413:174-179.

Cummings JA, Mulkey RM, Nicoll RA, Malenka RC (1996) Ca2 + signaling requirements for long-term depression in the hippocampus. Neuron 16:825-833.

Dalva MB, Takasu MA, Lin MZ, Shamah SM, Hu L, Gale NW, Greenberg ME (2000) EphB receptors interact with NMDA receptors and regulate excitatory synapse formation. Cell 103:945-956.

Davy A, Soriano P (2005) Ephrin signaling in vivo: look both ways. Dev Dyn 232:1-10.

Davy A, Aubin J, Soriano P (2004) Ephrin-B1 forward and reverse signaling are required during mouse development. Genes Dev 18:572-583.

Derkach VA, Oh MC, Guire ES, Soderling TR (2007) Regulatory mechanisms of AMPA receptors in synaptic plasticity. Nat Rev Neurosci 8:101-113.

Dong H, O’Brien RJ, Fung ET, Lanahan AA, Worley PF, Huganir RL (1997) GRIP: a synaptic PDZ domain-containing protein that interacts with AMPA receptors. Nature 386:279-284.

Egea J, Klein R (2007) Bidirectional Eph-ephrin signaling during axon guidance. Trends Cell Biol 17:230-238.

Georgakopoulos A, Litterst C, Ghersi E, Baki L, Xu C, Serban G, Robakis NK (2006) Metalloproteinase/presenilin1 processing of ephrinB regulates EphB-induced Src phosphorylation and signaling. EMBO J 25:1242-1252.

Grunwald IC, Korte M, Wolfer D, Wilkinson GA, Unsicker K, Lipp HP, Bonhoeffer T, Klein R (2001) Kinase-independent requirement of EphB2 receptors in hippocampal synaptic plasticity. Neuron 32:1027-1040.

Grunwald IC, Korte M, Adelmann G, Plueck A, Kullander K, Adams RH, Frotscher M, Bonhoeffer T, Klein R (2004) Hippocampal plasticity requires postsynaptic ephrinBs. Nat Neurosci 7:33-40.

Hayashi T, Huganir RL (2004) Tyrosine phosphorylation and regulation of the AMPA receptor by SRC family tyrosine kinases. J Neurosci 24:6152-6160.

Henderson JT, Georgiou J, Jia Z, Robertson J, Elowe S, Roder JC, Pawson T (2001) The receptor tyrosine kinase EphB2 regulates NMDA-dependent synaptic function. Neuron 32:1041-1056. 
Henkemeyer M, Itkis OS, Ngo M, Hickmott PW, Ethell IM (2003) Multiple EphB receptor tyrosine kinases shape dendritic spines in the hippocampus. J Cell Biol 163:1313-1326.

Kayser MS, McClelland AC, Hughes EG, Dalva MB (2006) Intracellular and trans-synaptic regulation of glutamatergic synaptogenesis by EphB receptors. J Neurosci 26:12152-12164.

Lee HK (2006) Synaptic plasticity and phosphorylation. Pharmacol Ther 112:810-832.

Lin D, Gish GD, Songyang Z, Pawson T (1999) The carboxyl terminus of B class ephrins constitutes a PDZ domain binding motif. J Biol Chem 274:3726-3733.

Lisman J (1989) A mechanism for the Hebb and the anti-Hebb processes underlying learning and memory. Proc Natl Acad Sci USA 86:9574-9578.

Liu L, Wong TP, Pozza MF, Lingenhoehl K, Wang Y, Sheng M, Auberson YP, Wang YT (2004) Role of NMDA receptor subtypes in governing the direction of hippocampal synaptic plasticity. Science 304:1021-1024.

Lu Q, Sun EE, Klein RS, Flanagan JG (2001) Ephrin-B reverse signaling is mediated by a novel PDZ-RGS protein and selectively inhibits $G$ proteincoupled chemoattraction. Cell 105:69-79.

Lu YM, Roder JC, Davidow J, Salter MW (1998) Src activation in the induction of long-term potentiation in CA1 hippocampal neurons. Science 279:1363-1367.

Luscher C, Nicoll RA, Malenka RC, Muller D (2000) Synaptic plasticity and dynamic modulation of the postsynaptic membrane. Nat Neurosci 3:545-550.

Makinen T, Adams RH, Bailey J, Lu Q, Ziemiecki A, Alitalo K, Klein R, Wilkinson GA (2005) PDZ interaction site in ephrinB2 is required for the remodeling of lymphatic vasculature. Genes Dev [Erratum (2006) 20:1829] 19:397-410.

Malenka RC, Bear MF (2004) LTP and LTD: an embarrassment of riches. Neuron 44:5-21.

Malenka RC, Nicoll RA (1999) Long-term potentiation-a decade of progress? Science 285:1870-1874.

Montgomery JM, Madison DV (2002) State-dependent heterogeneity in synaptic depression between pyramidal cell pairs. Neuron 33:765-777.

Morishita W, Lu W, Smith GB, Nicoll RA, Bear MF, Malenka RC (2007) Activation of NR2B-containing NMDA receptors is not required for NMDA receptor-dependent long-term depression. Neuropharmacology 52:71-76.
Muller D, Nikonenko I, Jourdain P, Alberi S (2002) LTP, memory and structural plasticity. Curr Mol Med 2:605-611.

Murai KK, Nguyen LN, Irie F, Yamaguchi Y, Pasquale EB (2003) Control of hippocampal dendritic spine morphology through ephrin-A3/EphA4 signaling. Nat Neurosci 6:153-160.

O’Dell TJ, Kandel ER (1994) Low-frequency stimulation erases LTP through an NMDA receptor-mediated activation of protein phosphatases. Learn Mem 1:129-139.

Osten P, Khatri L, Perez JL, Kohr G, Giese G, Daly C, Schulz TW, Wensky A, Lee LM, Ziff EB (2000) Mutagenesis reveals a role for ABP/GRIP binding to GluR2 in synaptic surface accumulation of the AMPA receptor. Neuron 27:313-325.

Palmer A, Zimmer M, Erdmann KS, Eulenburg V, Porthin A, Heumann R, Deutsch U, Klein R (2002) EphrinB phosphorylation and reverse signaling: regulation by Src kinases and PTP-BL phosphatase. Mol Cell 9:725-737.

Rodenas-Ruano A, Perez-Pinzon MA, Green EJ, Henkemeyer M, Liebl DJ (2006) Distinct roles for ephrinB3 in the formation and function of hippocampal synapses. Dev Biol 292:34-45.

Salter MW, Kalia LV (2004) Src kinases: a hub for NMDA receptor regulation. Nat Rev Neurosci 5:317-328.

Segura I, Essmann CL, Weinges S, Acker-Palmer A (2007) Grb4 and GIT1 transduce ephrinB reverse signals modulating spine morphogenesis and synapse formation. Nat Neurosci 10:301-310.

Takasu MA, Dalva MB, Zigmond RE, Greenberg ME (2002) Modulation of NMDA receptor-dependent calcium influx and gene expression through EphB receptors. Science 295:491-495.

Tremblay ME, Riad M, Bouvier D, Murai KK, Pasquale EB, Descarries L, Doucet G (2007) Localization of EphA4 in axon terminals and dendritic spines of adult rat hippocampus. J Comp Neurol 501:691-702.

Xia Z, Storm DR (2005) The role of calmodulin as a signal integrator for synaptic plasticity. Nat Rev Neurosci 6:267-276.

Yang SN, Tang YG, Zucker RS (1999) Selective induction of LTP and LTD by postsynaptic [Ca2+]i elevation. J Neurophysiol 81:781-787.

Zimmer M, Palmer A, Kohler J, Klein R (2003) EphB-ephrinB bidirectional endocytosis terminates adhesion allowing contact mediated repulsion. Nat Cell Biol 5:869-878. 